Books, videos, cd-roms, dvds and any other relevant items submitted for a review in the BDJ should be addressed to:

Mike Grace, Editor, British Dental Journal, 64 Wimpole Street WIG 8YS
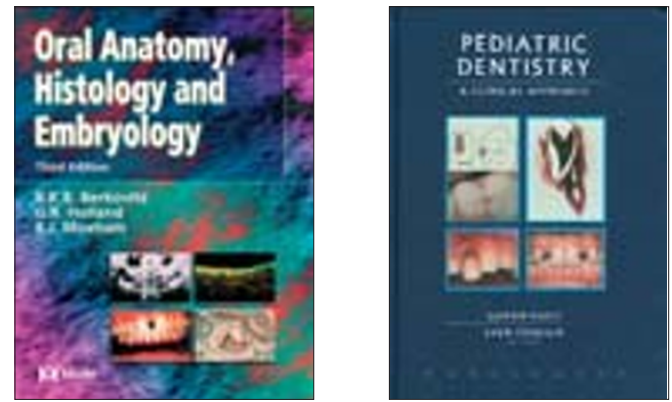

\section{Oral anatomy, histology and embryology}

\begin{tabular}{l} 
Berkovitz, Holland and Moxham (3rd ed) \\
London: Mosby, 2002 \\
price £44.99, pp392 \\
ISBN 0723431817 \\
\hline
\end{tabular}

The new edition of one of the favoured student texts in oral biology has updated this interesting and important area for undergraduates and postgraduates alike. The text provides a comprehensive overview of oral anatomy, including gross anatomy, histology and embryology. It also seeks to correlate the basic science information to clinical situations.

The book format has changed from the second edition, and it is now presented as a paperback, smaller in size than the previous edition. The text has been rewritten more as textbook than a colour atlas, and this makes the book more student friendly, without overburdening the reader with excess information. There are nearly 900 illustrations in the book, of which almost a third are new to this edition. Many of these new illustrations are reproductions of research findings from the contemporary literature. In addition, areas at the forefront of research, such as patterning in tooth development and the use of enamel matrix proteins in periodontal regeneration have been incorporated.

Chapters $1-6$ dealing with the macroscopic anatomy of the oral cavity and related areas have changed the least, however their new formatting makes the chapters easier to read. Whilst this edition represents a considerable improvement on the previous edition, it is clear that the authors' research interests have been represented. Some chapters contain many of their own research findings, with other chapters, such as that on the development of the face relatively short. To those without any prior knowledge, it makes it quite difficult to interpret, as there is relatively little basic embryology included in the text.

To incorporate the considerable amount of new material that has been added to the text, the section on comparative anatomy has been removed, and this largely mirrors the changes in curriculum that have been seen recently in many dental schools.

In conclusion, this book has been reformatted, with the addition of more contemporary research findings and many more illustrations and is more user friendly than the previous edition. R. Hall [BR5058]

\section{Pediatric dentistry: a clinical approach}

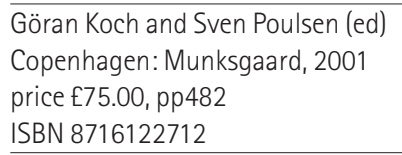

This book comprises 23 chapters by some 30 authors. It is a 'tour de force' of paediatric dentistry 'the European way'. But not quite. It is very much the 'Scandinavian way' with a few guest authors. Much of the Scandinavian way encompasses the 'American way'. Some of the authors have obtained part of their training in the USA and this is evident in some of the chapters.

The text is presented in an orthodox style with the early chapters being paediatric oral care - the perspectives, oral health in children and adolescents, mental aspects of development and physical development. These five chapters provide an excellent survey of all these aspects of child development and coupled with the chapter on behaviour management problems provide a sound theoretical and practical basis for practitioners in the specialty.

The next section covers the usual elements of patient assessment with history and examination, radiographic examination, pain control, caries management, endodontics, periodontal conditions and developmental disturbances of teeth. These cover the topics in considerable detail and also provide a good bibliography on the subjects covered. The chapter on prevention is placed here. It is always difficult to know where best this could go but it might be better placed juxtaposed to the chapter on oral health to emphasize the importance of prevention.

There are several chapters related to occlusion and this is perhaps where the American influence is most evident. The section on interceptive orthodontics lacks the evidence to support its widespread use. Nevertheless, the chapter is well written, clearly illustrated and is interesting.

Further chapters cover orodental trauma and follow up, oral mucous lesions, temporomandibular joint disorders and chronic health conditions, disabled children, and the dental team.

In summary, this text book provides us with a clear insight into clinical paediatric dentistry as practised in the Scandinavian countries. It is well illustrated, well written and covers the subject area well. It can be recommended to general practitioners who are interested in paediatric dentistry, specialist practitioners and postgraduate scholars studying for the specialty. It is also a source book for established consultants.

In this time of web based learning and interactive cd-roms it is pertinent to ask if the textbook is dead? Judging by this book the answer is quite clearly - not yet!

\section{G. J. Roberts [BR5000]}

